\title{
NIETZSCHE, HUME E A NATURALIZAÇÃO DAS PAIXÕES
}

\author{
Clademir Luis Araldi
}

UFPel

\begin{abstract}
RESUMO: Pretendemos confrontar a abordagem naturalista de Hume com a de Nietzsche, em relação ao modo como as paixões se conectam entre si. Enquanto Hume afirma o caráter desinteressado de certas paixões (particularmente de certas paixões sociais, comuns a todos os humanos), Nietzsche afirma como qualidade comum de todas as paixões, o impulso, a vontade de exercer o poder, que resulta na criação de valores e virtudes não morais. Consideramos que essa discordância da psicologia moral naturalista de Nietzsche em relação a Hume é relevante para o estudo das questões éticas.
\end{abstract}

PALAVRAS-CHAVE: paixões, ética, psicologia moral, naturalismo, valores.

ABSTRACT: We intend to confront the naturalistic approach of Hume to Nietzsche, in the way the passions are connected to each other. While Hume considers the disinterested character of certain passions (particularly of certain social passions, common to all humans), Nietzsche attributes as a common quality of all the passions, the drive, the desire to exercise power, which results in the creation of not moral values and virtues. We consider that this discrepancy between the naturalistic moral psychology of Nietzsche and Hume is relevant for the study of ethical issues. KEY-WORDS: passions, ethics, moral psychology, naturalism, values.

\section{I}

Uma das poucas referências positivas de Nietzsche a Hume pode ser encontrada num fragmento póstumo de 1885 (FP 11, 34 (70)1 ${ }^{1}$ Nele, é afirmado que a contribuição maior de Hume foi ter mostrado que é impossível pensar a priori, a partir de conceitos racionais, o nexo causal. Nesse contexto, o

\footnotetext{
1 Serão usadas as seguintes abreviaturas para citar as obras de Nietzsche: $\mathrm{HH}$ (Humano, demasiado humano), A (Aurora), GC (A gaia ciência), BM (Além do bem e do mal), GM (Genealogia da moral), Cl (Crepúsculo dos ídolos) e FP, para os fragmentos póstumos por nós traduzidos da Kritische Studienausgabe (KSA).
} 


\section{Dossiê Naturalismo, Dissertatio - Volume Suplementar 02 UFPel [2015]}

filósofo escocês é caracterizado como "uma das cabeças mais sutis" do séc. XVIII. Entretanto, no período genealógico, o filósofo alemão define Hume, juntamente com Hobbes e Locke, como responsável pelo "rebaixamento e diminuição do conceito do filósofo por mais de um século". (BM, 252) Isso é compreensível, tendo em vista o esforço de distanciamento dos psicólogos morais ingleses (e de P. Rée, autor de $A$ origem dos sentimentos morais), mas encobre uma assimilação indireta de elementos centrais da teoria das paixões e da moral de Hume, em obras como Humano, demasiado humano e Aurora. É o modo próprio com que Nietzsche reelabora a conexão entre as paixões, e das paixões com os sentimentos e valores morais que pretendemos analisar aqui, a partir do confronto com o naturalismo de Hume.

\section{II}

Podemos encontrar em Nietzsche e em Hume uma psicologia moral naturalista, em que as paixões exercem função predominante na determinação das ações humanas ${ }^{2}$. No Tratado da natureza bumana (TNH), Hume procurou provar empiricamente que as ações dos homens têm uma união constante com os motivos, com o caráter e com as circunstâncias neles envolvidos ${ }^{3}$. Apesar da irregularidade e da inconstância aparentes da conduta humana, poder-se-ia explicar a necessidade das ações humanas, sem recorrer à Razão. Essa psicologia moral naturalista ${ }^{4}$ será radicalizada por Nietzsche, à medida que ele

${ }^{2} \mathrm{~A}$ paixão é considerada por Hume como causa das ações, e também como princípio, motivo que dirige a Vontade (cf. TNH, Livro 2, Parte 3, seção 2, Dos motivos que influenciam a vontade). Doravante, os algarismos arábicos que se seguem à abreviatura da obra indicam o livro, a parte e a seção, respectivamente.

${ }^{3}$ /dem, Hume, 2009, p. 437 (TNH 2, 3, 1).

${ }^{4}$ Craig Beam enfatiza a proximidade entre Hume e Nietzsche enquanto "filósofos da natureza humana", mas afirma a pretensão de Nietzsche de avançar na pesquisa histórica e psicológica, inclusive em relação a seu 'predecessor' escocês: "Just as Hume wanted to break with abstract metaphysics and inaugurate a new Science of human nature, Nietzsche saw himself as the first philosopher to give proper attention to historical and psychological factors". (Beam, 1996, p. 301) 
desenvolve o método genealógico, desde as ciências mais influentes de sua época, nomeadamente, a Psicologia empírica francesa, a Fisiologia e a História.

Segundo Hume, o embate próprio e determinante se daria entre paixões fortes e fracas, ou entre as calmas e violentas, desvinculado de qualquer faculdade ou fundamento extrínsecos à Natureza Humana (sentimentos morais (moral feelings) são próprios da Natureza Humana). Ele critica severamente as pretensões da filosofia racionalista, de regular as ações pela Razão. Por si só, a razão jamais pode ser motivo para uma ação da vontade humana (TNH 2, 3, 3). O necessitarismo aplicado às ações serve para explicar o modo como os objetos nos afetam, a partir das impressões que resultam imediatamente do prazer e da dor. $\mathrm{Na}$ complexa relação entre impressões e ideias, é a paixão que se coloca como princípio da ação.

A ciência empírica do homem deveria causar uma revolução na filosofia moral, impossibilitando-a de operar a priori. Como enfatizou B. Stroud, segundo Hume, nós somos naturalmente constituídos de características que nos fazem sentir do modo como sentimos ${ }^{5}$. Do mesmo modo como explana a experiência humana a partir das percepções simples e do princípio de associação de ideias, também os sentimentos e comportamentos morais são explanados como combinações de impressões e ideias na mente.

Se os seres humanos são dotados naturalmente de certas paixões, compreendidas como "existências originais", é preciso descrever como as ações, sentimentos e pensamentos se inserem e interagem no curso necessário do mundo. Hume pressupõe (e expõe de modo fragmentário) uma estrutura fixa de paixões, o que permitiria classifica-las. Nessa perspectiva, é possível encontrar em Hume três ou quatro tipos principais de paixões. Segundo John Rawls são três:

5 Cf. Stroud, 2013, p. 10. Rawls denomina "fideísmo da natureza" o equilíbrio entre as forças psicológicas da imaginação e do hábito com as reflexões filosóficas 'céticas' de Hume. Esse 'fideísmo' seria decisivo para o naturalismo psicológico humiano. Cf. Rawls, 2005, p. 30 s. 


\section{Dossiê Naturalismo, Dissertatio - Volume Suplementar 02 | UFPel [2015]}

1. Paixões originais (primárias)

2. Paixões Secundárias diretas e

3. Paixões Secundárias Indiretas ${ }^{6}$.

Segundo N. Kemp Smith, Hume menciona quatro tipos de paixão no Tratado da natureza bumana:

1. As Paixões Primárias (the primary passions), procedentes de um "impulso natural completamente inexplicável”;

2. As Paixões Secundárias Diretas (violentas): desejo - aversão; tristeza - alegria; esperança - medo, que procedem diretamente da dor e do prazer (pain and pleasure); incluem a volição ou vontade (the Will), que é simples, e possui um caráter distinto de todas as outras;

3. As Paixões Secundárias Indiretas (amor - ódio; orgulho humildade) originam-se do prazer e da dor, mas requerem condições mais complexas, "a dupla relação de impressões e ideias";

4. As Paixões Secundárias Diretas (calmas). Elas procedem tb. do prazer e da dor, mas de um modo especial: da contemplação de ações e objetos externos. Tratam-se dos sentimentos morais e estéticos, de dois modos básicos de aprovação e desaprovação: i) do deleite com o belo e da repulsa ao feio, e ii) do louvor na

${ }^{6} \mathrm{~A}$ distinção entre paixões fortes e fracas se aplicaria, segundo Rawls, a esses 3 tipos principais (cf. Rawls, 2005, p. 34).

7 Ao tratar das paixões diretas (de desejo e aversão, de tristeza e alegria, de esperança e medo, "juntamente com a volição") na seção 9, Hume diz que elas "decorrem do bem e do mal de maneira mais natural e sem preparação" (§ 2). Entretanto, no § 8, ele afirma que "além do bem e do mal, ou, em outras palavras, da dor e do prazer, as paixões diretas surgem frequentemente de um impulso natural ou instinto inteiramente inexplicável". Questiono assim, se "o desejo de punição de nossos inimigos, e da felicidade de nossos amigos", além da "fome, desejo carnal e outros apetites corpóreos", não seriam um tipo especial de paixões diretas, ao invés de constituir uma classe distinta de "paixões originais" (cf. TNH $2,3,9)$. 
presença da virtude e censura na presença do vício ${ }^{8}$. Segundo Rawls, tratar-se-ia ali de paixões indiretas, frequentemente calmas.

A inserção da vontade e dos sentimentos morais nas paixões diretas é problemática na psicologia moral humiana, à medida que questionamos se há uma Natureza que simplesmente estabeleceu uma conexão entre nossas paixões e "certos fins objetivos" (como também questiona Kemp Smith), p. ex., a pressuposição de que há um altruísmo original e invariável no amor. Essa estrutura e configuração de paixões, pré-determinada na natureza humana, excede os limites de uma psicologia moral naturalista.

A simpatia (the sympatby) é determinante no mecanismo de associação das paixões. Apesar de não ser uma paixão, a simpatia (qualidade notável da natureza humana), possui importantes funções morais. Enquanto mecanismo, princípio de comunicação entre as paixões, a simpatia realiza a "conversão de uma ideia numa impressão, pela força da imaginação" (TNH 2, 3, 6). Ela não altera diretamente a força da paixão, pois isso depende do caráter do indivíduo e da posição e natureza do objeto. Mas é de fundamental importância para determinar o modo como as paixões calmas podem predominar sobre as paixões violentas, no TNH. Ela é a fonte de apreço "por todas as virtudes artificiais" (TNH 3, 3, 10). Novamente, esse "princípio muito poderoso da natureza humana" parece ser original, primário, sem história, produzindo "nosso sentimento de moralidade em todas as virtudes artificiais" (e naturais também). Somente por simpatia, o bem da sociedade (alheio a nosso interesse) agrada.

É fácil perceber que Nietzsche não concorda com o estatuto desse "sentimento natural de aprovação e desaprovação". Para Hume, originário é o princípio da simpatia, que "que nos leva a sair de nós mesmos, e sentir prazer

${ }^{8}$ Cf. Kemp Smith, 2005, p. 168. 


\section{Dossiê Naturalismo, Dissertatio - Volume Suplementar 02 | UFPel [2015]}

ante caracteres úteis à sociedade" (TNH 3, 3, 11). Segundo Nietzsche, o sentimento da simpatia não é natural. Natural é o temor e antipatia em relação ao estranho. (FP, 4 [123] - verão de 1880 ). Esse sentimento dificilmente ocorria nos tempos selvagens e guerreiros. À diferença de nossa época, demasiado sensível, com seu amolecimento doentio. Entretanto, Sócrates e o cristianismo teriam já derivado da simpatia a moral inteira. Para Nietzsche, toda moral elevada e nobre procede do pathos da distância.

Para Nietzsche, o medo é o pai da moral. O medo ante o incerto, ante outros homens, ante a natureza, fez com que o homem primitivo (sem discernimento da causalidade efetiva) se submetesse a regras de uma autoridade superior. O filósofo alemão opera com as noções de sentimento de poder (Gefübl der Macht) em 1877, de prazer no poder, de medo (Furcht) e vontade de poder (Wille zur Macht) em sua hipótese genealógica - psicológica. O prazer no poder decorre sempre do desprazer na impotência (Unlust an der Ohnmacht). O vínculo dos sentimentos morais com a sociabilidade é determinante, pela alta estima dos seres humanos pela opinião dos outros (nota-se aqui a influência de P. Rée).

Apesar de não haver, explicitamente, uma classificação das paixões, Nietzsche assim as divide: 1) Em sua fase inicial, as paixões tendem à estupidez. São as paixões violentas e fortes do homo natura, como fome, sede, satisfação dos instintos sexuais, autopreservação; 2) Em sua fase tardia, as paixões desencadeiam dois processos distintos: i) na moral dos escravos, há uma moralização (enfraquecimento) das paixões; ii) na moral dos nobres, há um fortalecimento (espiritualização) das paixões.

Um exemplo da diferença na classificação e valoração das paixões nos dois filósofos é o ressentimento. Para o filósofo escocês, o ressentimento é um instinto original (paixão primária, calma). Para Nietzsche, o ressentimento é um sentimento moral bem tardio, alojado na moral dos 
escravos, como reação aos valores e tipos mais fortes, dos nobres. O homo natura expressaria, a partir de si mesmo, seus impulsos expansivos e dominadores. A moral seria somente uma linguagem simbólica de seus impulsos e afetos.

Tomemos outro exemplo: o medo. Para Hume o medo diante de acontecimentos incertos e prováveis é uma paixão direta, negativa. No caso do exemplo citado da parte 3 do livro 2 (Seção 4. Das causas das paixões violentas) é trazido o exemplo do soldado, que é possuído pelo "medo e terror ao pensar em seus inimigos". Emoções, como a de perceber a grandeza e o poder do inimigo, aumentam o medo, por relações de ideias, que se torna paixão predominante. Nietzsche concordaria com isso (apesar de não operar com a relação de ideias) e atribui esse vínculo à origem dos sentimentos morais (dos fracos, escravos). O nobre, no entanto, consegue afirmar a força que sente dentro de si, através de valores e ações. O medo dá origem à moral dos escravos. O temor ao outro está na origem dessa moral, que depois glorifica o altruísmo. Uma diferença decisiva sobressai nessa comparação: enquanto Hume possui uma concepção fraca de vontade, articulada com a qualidade da simpatia, Nietzsche propõe uma compreensão forte e abarcante, para dar conta de sua explicação psicológica da moralidade em chave naturalista, desvinculando a simpatia da compaixão e de outros laços morais, dos quais ele quer se livrar.

\section{III}

Importa-nos, especialmente, analisar o caráter desinteressado das paixões e a afirmação de que as paixões sociais são iguais em todos os homens ${ }^{9}$. Por que Nietzsche ressalta o caráter egoísta das paixões? Há, assim, um ponto de discordância entre Nietzsche e Hume no modo de formular o

${ }^{9}$ Cf. Kemp Smith, 2005, p. 139 e 153. 


\section{Dossiê Naturalismo, Dissertatio - Volume Suplementar 02 | UFPel [2015]}

naturalismo, e de operar a psicologia moral. Se o ceticismo mitigado de Hume comporta valores e virtudes positivamente vinculados à natureza humana, o niilismo radical nietzschiano, desenvolvido a partir das obras genealógicas em questão, é um empecilho para a validade intersubjetiva dos valores e virtudes ${ }^{10}$.

\section{IV}

O novo método de investigar as paixões humanas, presente desde Humano, demasiado bumano (1878), está fortemente ligado às noções de prazer e desprazer (Lust und Unlust). Nessa investigação de cunho preponderantemente psicológico, todas as ações individuais humanas teriam como meta o prazer e a fuga da dor. Não haveria uma distinção (moral) entre 'boas' e 'más' ações, pois todas elas são motivadas pela busca individual da obtenção e incremento do prazer: “Todas as 'más' ações são motivadas pelo impulso de conservação ou, mais exatamente, pelo propósito individual de buscar o prazer e evitar o desprazer" (HH I, 99).

Essa análise psicológica é articulada com considerações históricas, à medida que Nietzsche vincula a formação do sentimento moral com as sensações prazerosas que o indivíduo encontra em si mesmo, e com os novos tipos de prazer advindos da longa história da formação da sociabilidade. Foi sempre a obstinada busca de prazer que moveu os indivíduos a controlar as paixões próprias que poderiam impedir o acesso a novas fontes de prazer, à medida que suas paixões colidem com outras individualidades, com o mesmo objeto de desejo (p. ex., de uma propriedade). O "instinto social"11 surge como

10 David C. Hoy contrapõe Nietzsche a Hume, tendo como preocupação precípua as condições de justificação do método genealógico. Enquanto Hume visa a uma descrição neutra dos valores, Nietzsche acaba por sobrecarregar valorativamente a genealogia (HOY, 1994, p. 252).

11 Paul Rée, convicto seguidor da teoria da evolução de Darwin, afirma na obra Der Ursprung der moralischen Empfindungen que o instinto social (nas formigas, abelhas) é o desenvolvimento do instinto materno, que por sua vez é fortalecido pela seleção natural. Esse impulso natural para cuidar dos outros torna-se um fenômeno moral no mundo humano. Assim se explicam as sensações prazerosas 
uma nova forma de prazer, adquirida com esforços contínuos e múltiplos. A ampliação do domínio das sensações de prazer decorrente das relações humanas tornou o homem "melhor" em relação ao estado natural précivilizatório. A segurança e o bem-estar em desfrutar prazeres comuns diminuíram a hostilidade "natural" entre os humanos, graças à ficção emergente da empatia:

As manifestações de prazer semelhantes despertam a fantasia da empatia (Phantasie der Mitempfindung), o sentimento de ser igual: o mesmo fazem os sofrimentos comuns, as mesmas tormentas, os mesmos perigos e inimigos. Com base nisso se constrói depois a mais antiga aliança: cujo sentido é defender-se e eliminar conjuntamente um desprazer ameaçador, em proveito de cada indivíduo. E assim o instinto social nasce do prazer. (HH I, 98)

O que conta nessa perspectiva filosófica é a manutenção e o incremento do poder do indivíduo. Tanto no estado anterior à sociabilidade quanto na história da moralização. Nas presumíveis ações "más", que teriam como meta o sofrimento alheio, e nas ações compassivas, que, ao contrário visam o bem do outro (na diminuição de seu sofrimento), estariam em jogo apenas diversos elementos de prazer pessoal, que no fundo expressam o prazer no exercício do poder, da superioridade em relação ao que sofre. Ser causa do sofrimento do outro ou querer aliviar sua dor seriam formas de ações egoístas (cf. HHI, 103).

A coerção do 'indivíduo coletivo' sobre os seres humanos individualizados é vista como necessária para o surgimento da moralidade (cf. HH I, 99). O processo da eticidade (Sittlichkeit) opera uma transformação radical, à medida que a coerção torna-se costume. A força do hábito e dos costumes tornaria prazerosa a prática de ações, que bem mais tarde passam a ser chamadas de "morais". O caráter ético (sittlich) de uma ação, desse modo, é Rée e Nietzsche foram muito importantes na elaboração de Humano, demasiado humano. 


\section{Dossiê Naturalismo, Dissertatio - Volume Suplementar 02 | UFPel [2015]}

constituído pelo efeito prazeroso dos costumes. Nietzsche, entretanto, diz que o hábito, por ser um gênero de prazer, é “fonte da moralidade” (Quelle der Moralität). Hábitos praticados de bom grado não são apenas agradáveis, mas também úteis. Assim, após muitas repetições, os hábitos que valem para os indivíduos como sua única condição de existência são adotados por uma comunidade ou povo, constituindo sua eticidade (cf. HH I, 97). É no indivíduo, contudo, que os hábitos (ligados a costumes legitimados socialmente) prazerosos serão sentidos como morais ${ }^{12}$. É o sentimento, potencializado pela apreciação e valoração subjetivas das ações prazerosas, que engendra o caráter moral das mesmas (N.B. não há contemplação, perspectiva de terceira. pessoa, de um espectador judicioso). Nesse ponto já nos deparamos com a interrogação: esse processo denota um domínio moral objetivo das ações ou é somente um âmbito valorativo, próprio de um indivíduo que estima e interpreta seguindo convenções socialmente aceitas? Por se sentir valioso e vinculado a uma comunidade, o indivíduo decidiria espontaneamente obedecer a valores e leis de uma comunidade moral. O prazer no costume constituiria uma espécie de segunda natureza. Longe de defender um cirenaísmo na ética, o autor de Humano pretende atingir formas elevadas, sutis e espirituais de prazer. O prazer, especialmente o prazer no exercício do poder, é o critério para a valoração das ações. Prazer, no sentido aqui apontado, não é um mero epifenômeno dos impulsos, não é um sentimento ou uma sensação decorrente, mas está intrinsecamente ligado aos impulsos naturais, originais, dominadores e expansivos. O prazer no exercício do poder possuiria, nessas considerações escassamente naturalistas, um valor intrinseco.

$\mathrm{Na}$ conceitualização da eticidade do costume, Nietzsche procura articular uma abordagem histórica pretensiosa (que incide sobre os milênios de

12 Nietzsche não explica, a meu ver, como e por que o indivíduo pode ou quer sentir como morais hábitos que lhe são prazerosos. 
constituição dos modos humanos de vida) com considerações psicológicas e filosófico-morais:

\begin{abstract}
Em relação ao modo de vida de milênios inteiros da humanidade, nós, homens de hoje, vivemos numa época muito pouco ética (in einer sebr unsittlichen Zeit): o poder do costume está espantosamente enfraquecido, e o sentimento da eticidade (Sittlichkeit), tão refinado e posto nas alturas, que podemos dizer que se volatilizou. Por isso vêm a ser difícil para nós, que nascemos tardiamente, as percepções fundamentais sobre a gênese da moral; (...). ( $A, 9)$.
\end{abstract}

Com essa percep̧ão fundamental especulativa de que o caráter próprio da humanidade foi fixado nesse longo período da eticidade do costume (que seria muito mais vasto e determinante do que é admitido na genealogia utilitarista de Hume), ele conclui que até Sócrates e a moral dele advinda, o indivíduo, com pretensão de liberdade, originalidade e autonomia é avaliado como não ético. Se eticidade é "obediência a costumes", toda posição valorativa estritamente individual é condenável. O círculo da eticidade, que compreendia vastos domínios, como educação, saúde, linguagem etc., fecha-se na estrita obediência às leis e aos costumes. Por serem a "maneira tradicional de agir e avaliar" ( $A$, 9), os costumes impedem qualquer afirmação de ações, caracteres e modos de ações radicalmente individuais. A autoridade superior da tradição possibilitou a decisiva transmutação dos impulsos da natureza (originária) humana em costumes prazerosos, sentidos e avaliados como éticos, ou seja, vinculados a formas de vida tradicionais.

Nietzsche também concordaria que emoções, impulsos e sentimentos determinam os juízos morais, mas também afirma que, nessa relação complexa e reversível, os impulsos são transformados pelos juízos morais. (cf. $A, 45$ ). Nessa nova compreensão dos impulsos, na obra Aurora, Nietzsche pretende avançar em relação ao naturalismo de Hume.

Os costumes poderiam, assim, atuar sobre a natureza originária dos instintos, transformando-os. Essa é a preocupação do filósofo de Sils-Maria no 


\section{Dossiê Naturalismo, Dissertatio - Volume Suplementar 02 | UFPel [2015]}

aforismo de Aurora, que leva o título "Os impulsos transformados pelos juizos morais". Nele são expostas transmutações decisivas dos impulsos originais do ser humano, até assumirem uma conformação diversa, a saber, uma segunda natureza (eine zweite Natur). Em si e para si mesmos, os impulsos não possuem nenhum caráter ou denominação moral. Através da influência dos costumes (das impressões individuais de louvor e censura que deles decorrem), desenvolvem-se sentimentos agradáveis, como a humildade, ou desagradáveis, como a covardia, que passam por um processo de moralização, sendo por fim ajuizados como bons ou maus. Os juízos de valor moral bom e mau, por sua vez, procedem de modos de viver e de avaliar determinados. Os modos de vida dos nobres, com seus traços típicos de caráter, p. ex., constituem costumes e avaliações tidos como superiores e preponderantes. Nesse movimento, os impulsos em questão adquirem como que uma 'segunda natureza' por meio da "sensação concomitante de prazer ou desprazer"(cf. $A$, 38).

\section{V}

Os sentimentos morais são vistos como expressões de desejos de exercer poder sobre outros. Fazer bem e mal a outros são formas de exercer o poder sobre eles. Na obra que fecha o período da filosofia do espírito livre, $A$ gaia ciência, o filósofo solitário propõe uma "teoria do sentimento de poder", em que dor e prazer são instrumentos para aumentar o poder (cf. GC, 13). Não encontramos ali, contudo, a pedra de toque do pensamento ético nietzschiano. Essa psicologia dos impulsos morais não expõe como surgem os valores, a partir das avaliações e formas de vida. Tudo dependeria apenas de como o indivíduo "tempera a sua vida". Ou seja, é uma questão de gosto, do temperamento de indivíduos, tanto dos nobres quanto dos compassivos (o 
deleite com suas próprias ações belas). Dos sentimentos de dor e prazer não se depreendem naturalmente valores e virtudes tipicamente morais.

$\mathrm{Na}$ segunda dissertação da Genealogia da moral, entre os parágrafos 2 e 12, principalmente, Nietzsche retoma a noção de eticidade do costume, desta fez remodelada com a fisiopsicologia da vontade de poder. A obediência às leis e aos costumes é ainda vista como 'natural'. Seguindo a orientação de Bem e Mal, 5, o "imperativo categórico da natureza", ou seja, o lento e contínuo trabalho do homem-natureza, enquanto gênero, sobre e nos indivíduos, leva à formação da cultura e, por fim, ao "indivíduo soberano", que não se submete às leis e convenções da moralidade e da sociabilidade. É uma diferença significativa em relação ao fideísmo da natureza de Hume, no qual as paixões calmas e sociais, e as virtudes sociais a elas conectadas, depreendem-se direta ou indiretamente da natureza humana, da propensão natural a certos sentimentos morais e virtudes, que favorecem interesses e bens comuns da sociedade. A concepção "tirânica" de Natureza em Nietzsche é elaborada a partir da crueldade e violência "naturais", que resultam da ação da vontade de poder no longo período da eticidade do costume e no limiar do período moral, ou seja, da história da civilização. Essa concepção de natureza implica em separar os valores dos nobres, enraizados em formas 'naturais' de vida, do domínio estrito da moralidade, ou seja, das avaliações e valores dos fracos, e dos conceitos dali emergentes, como responsabilidade moral, culpa, livrearbítrio.

A crueldade e violência, que para Hume (assim como para Schopenhauer) seriam motivações não morais, ou até mesmo antimorais, são para Nietzsche determinantes para a formação de valores morais 'naturalistas'. Elas são expressão de forças ativas do nobre, de seu pathos da distância. A negação do caráter cruel e violento da natureza humana constitui o campo da moralidade dos escravos. Antes de ser uma paixão-fundamento, a simpatia, e a 


\section{Dossiê Naturalismo, Dissertatio - Volume Suplementar 02 | UFPel [2015]}

compaixão dela derivada, seriam expressões de uma vontade moral de tiranizar os impulsos, ou melhor, de reduzi-los a uma "mediania inócua".

À diferença da compreensão de vontade do Hume do Tratado, Nietzsche aponta em Além do bem e do mal para a complexidade da "vontade": em todo querer há uma multiplicidade de sensações e um pensamento que comanda. Nesse sentido, "a vontade não é apenas um complexo de sentir e pensar, mas sobretudo um afeto: aquele afeto do comando" (BM, 19). A unidade relativa homem, ao querer, "comanda algo dentro de si que obedece". Ao compreender a moral como "teoria das relações de dominação sob as quais se origina o fenômeno 'vida", Nietzsche já insere sua própria posição (sua preferência valorativa) nos assuntos a serem investigados. Esse é o partis pris da genealogia nietzschiana da moral. Nesse ensaio, é preciso abandonar o conceito sintético de eu, para compreender o homem como dividuum, na medida em que ele é a parte que comanda e a parte que obedece. O corpo, "uma estrutura social de muitas almas", ou seja, de muitas vontades, é o ponto de partida para a construção desse projeto de naturalização da moral ${ }^{13}$. Mandar e obedecer seriam essenciais de todo o querer. A moral passa a ser vista como uma configuração singular do mundo constituído substancialmente de "vontades".

No início da obra, o crítico da metafísica buscou sua nova orientação metodológica na fisiologia. É da natureza de cada impulso querer dominar, de modo que cada ser vivo quer sobretudo "dar vazão a sua força" (BM, 13). Ele parece já estar assegurado nesse ponto da argumentação, de que "a própria vida é vontade de poder". Ao aliar a psicologia à fisiologia no final do capítulo I, é reforçada a pretensão de dar conta dos problemas fundamentais da

13 Janaway aponta para as dificuldades que Nietzsche encontra na Genealogia da moral para construir um modo não moral de avaliar, sem precisar das noções tradicionais de 'consciência', 'alma' e 'eu': "Nietzsche appears to require a unified self of a kind that his oficial view would deny". (Janaway, 2007, p. 222). A questão não é de modo algum resolvida com a afirmação de que "os instintos valoram", ou de que o Selbst pode ser dissolvido na multiplicidade de impulsos, cada um com sua perspectiva. 
filosofia do futuro. Essa fisiopsicologia, vista como "morfologia e teoria da evolução da vontade de poder" (BM, 23) seria o caminho promissor para a naturalização da moral. Para além dos preconceitos e fundamentos morais, o fisiopsicólogo poderia agora compreender a natureza valorativa e dominadora dos impulsos humanos. O parágrafo 36 de Bem e mal expressa de forma breve um longo caminho de investigação, em que a vontade de poder opera como impulso constitutivo de todo acontecer no mundo e de todas as formações morais. A nova compreensão de vontade, que não se baseia mais nas relações entre prazer e dor, mas como vontade de poder, de vencer resistências, marca uma separação em relação ao naturalismo de Hume, pois o filósofo alemão pretende, com sua fisiopsicologia dos impulsos, elaborar uma tipologia da moral. Assim, todas as paixões seriam transformações da vontade de poder (operando em seu modelo antropológico), que se expressam em valores afirmativos ou negativos, dependendo do modo de vida, melhor dizendo, da constituição fisiopsicológica de cada ser humano.

\section{VI}

Confrontada com a noção de simpatia de Hume, enquanto mecanismo de associação, que "permite receber por comunicação" sentimentos e afetos de outras pessoas, a vontade de poder nietzschiana, enquanto multiplicidade de impulsos, de caráter perspectivista, em contínua luta pelo aumento do poder, deveria ser a chave para a solução ao grandioso problema da origem da moral.

Nesse sentido, em Para além de bem e mal, 225, o filósofo alemão pretende realizar um acerto de contas com concepções morais, entre as quais estaria também as do filósofo escocês em questão. Ele critica ali o utilitarismo, o hedonismo (juntamente com o pessimismo e o eudaimonismo) por buscarem no prazer e na dor a "medida de todas as coisas". Em face dessa 


\section{Dossiê Naturalismo, Dissertatio - Volume Suplementar 02 | UFPel [2015]}

pretensa ingenuidade, o psicólogo-genealogista-naturalista tem consciência de quais são as forças configuradoras do mundo humano, quais sejam, as vontades de poder. Não é somente o "anatomista da moral” que fala aqui, mas sobretudo o artista, ou no máximo, o pensador com consciência de artista (Künstler-Gewissen). Contra as tendências morais modernas que propõem minimizar os sofrimentos e maximizar o bem-estar, Nietzsche propõe a disciplina do grande sofrimento, pautada na vontade de poder. Não há espaço aqui para a compaixão para com as fraquezas humanas, nem para perspectivas em terceira pessoa. Em cada ser humano singular se dão criatura e criador, cada um teria a tarefa de configurar seus próprios impulsos. Isso torna difícil situar a explicação naturalista da moral em Nietzsche no plano estritamente ético.

Enquanto Hume destaca o caráter desinteressado de certas paixões (particularmente de paixões sociais, comuns a todos os humanos), Nietzsche afirma como qualidade comum de todas as paixões, o impulso, a vontade de exercer o poder, que resulta na criação de valores e virtudes (não morais). É esse ponto de discordância entre as psicologias morais naturalistas de Nietzsche e Hume que pretendi apontar aqui como decisivo.

Naturalizar a genealogia de Nietzsche significa retomar o intento naturalista de Hume, de modo a fornecer uma análise psicológica coerente da moral. Nesse ponto, temos um impasse significativo entre os projetos naturalistas de Hume e de Nietzsche. O filósofo alemão não aceitaria a classificação das paixões do filósofo escocês, por ela ser tendenciosamente conduzida por um interesse moral oculto, a saber, o de enfatizar as paixões calmas na ética. Com auxílio da doutrina da simpatia, o escocês pretenderia garantir o acesso às virtudes naturais e artificiais. Toda paixão, todo impulso que se desenvolve em valor e em virtude, não é para Nietzsche uma impressão de reflexão, mas possui simplesmente a qualidade única de tudo o que vive, sente e quer: a intensificação do poder. Esse seria o traço básico da 
fisiopsicologia dos impulsos de Nietzsche, com sua pretensão de mostrar a efetividade desse impulso ao poder, enquanto fato fisiológico. A vontade de poder permanece uma hipótese não naturalizável na obra de Nietzsche, apesar de seus esforços genealógicos. As análises de Nietzsche, assim como as de Hume, estariam contaminadas por distintas e inconciliáveis preferências valorativas, que determinam suas investigações da moral.

\section{REFERÊNCIAS BIBLIOGRÁFICAS}

ACAMPORA, Christa D. (org.) Nietssche's On the Genealogy of Morals. Critical Essays. Lanham: Rowman \& Littlefield Publishers, 2006.

ARALDI, Clademir L. "A vontade de potência e a naturalização da moral". Cadernos Nietzsche 30, 2012. São Paulo: GEN. Disponível em http://www.cadernosnietzsche.unifesp.br/

BEAM, Craig. "Hume and Nietzsche: Naturalists, Ethicists, Anti-Christians". Hume Studies, vol. XXII, n. 2 (Nov., 1996), p. 299-324.

BRITO, Adriano N. de. "Falácia Naturalista e naturalismo moral: Do é ao deve mediante o quero". Belo Horizonte, Kriterion, vol. 51, no. 121, 2010, p. 215 226.

CLARK, Maudemarie. "Nietzsche's Immoralism and the Concept of Morality". In SCHACHT, Richard. (org.). Nietzsche, genealogy, morality: essays on Nietzsche's Genealogy of Morals. Londres: University of California Press, 1994.

HÖFE, Otfried (org.). Zur Genealogie der Moral. Berlim: Akademie Verlag, 2004.

HOY, David C. "Nietzsche, Hume and the Genealogical Method". In SCHACHT, Richard. (org.). Nietzsche, genealogy, morality: essays on Nietzsche's Genealogy of Morals. Londres: University of California Press, 1994.

HUME, David. A Treatise of Human Nature. New York: Dove Publications, 2003.

HUME, D. Tratado da natureza bumana. 2. ed. São Paulo: Ed. UNESP, 2009.

HUME, David. An Enquiry Concerning the Principles of Morals. Oxford: Oxford University Press, 1998.

HUME, David. A Dissertation on the Passions. Ed. por Tom Beauchamp. Oxford University Press, 2009. 


\section{Dossiê Naturalismo, Dissertatio - Volume Suplementar 02 | UFPel [2015]}

JANAWAY, Christopher. Beyond Selflessness: Reading Nietæsche's Genealogy. New York: Oxford University Press, 2007.

KEMP SMITH, Norman. The Pbilosophy of David Hume. A critical study of its origins and central doctrines. With a new introduction by Don Garret. Londres: Palgrave Macmillan, 2005.

LEITER, B.; SINHABABU, N. (orgs.). Nietzsche and Morality. New York: Oxford University Press, 2007.

LEITER, Brian. Nietzsche on Morality. New York: Routledge, 2002.

MAGNUS, B.; HIGGINS, K. (Ed.). The Cambridge Companion to Nietzsche. Cambridge: Cambridge University Press, 1996.

NIETZSCHE, F. W. A genealogia da moral. Trad. de Paulo C. de Souza. São Paulo, Companhia das Letras, 1998.

NIETZSCHE, F. W. Além do Bem e do Mal. Prelúdio a uma Filosofia do Futuro; trad. de Paulo C. de Souza. São Paulo: Companhia das Letras, 1992.

NIETZSCHE, F. W. Aurora. Trad. de Paulo C. de Souza. São Paulo, Companhia das Letras, 2004.

NIETZSCHE, F. W. Humano, demasiado humano. Trad. de Paulo C. de Souza. São Paulo, Companhia das Letras, 2000.

NIETZSCHE, F. W. Sämtliche Werke. Kritische Studienausgabe (KSA). 15 vols. Organizada por Giorgio Colli e Mazzino Montinari. Berlim: de Gruyter, 1988.

NORTON, D. F. (ed.). The Cambridge Companion to Hume. Nova York: Cambridge University Press, 1993.

PRINZ, Jesse J. The Emotional Construction of Morals. Oxford: Oxford University Press, 2007.

RAWLS, John. História da filosofia moral. São Paulo: Martins Fontes, 2005.

SCHACHT, Richard. (org.). Nietzsche, genealogy, morality: essays on Nietzsche's Genealogy of Morals. Londres: University of California Press, 1994.

SCHOPENHAUER, Arthur. Sobre o fundamento da moral. São Paulo: Martins Fontes, 2001.

STROUD, Barry. Hume. Londres/Nova York: Routledge, 2003. 